\title{
Laboreal
}

Volume 4 N$^{\circ} 2$ | 2008

A inovação

\section{A Terceirização no Brasil : velho e novo fenômeno}

La subcontratación em Brasil : viejo e nuevo fenómeno

La sous-traitance au Brésil : vieux et nouveau phénomène

Service outsourcing in Brazil : old and new phenomenon

\section{Graça Druck e Tânia Franco}

\section{(2penEdition}

\section{Journals}

\section{Edição electrónica}

URL: http://journals.openedition.org/laboreal/11413

DOI: $10.4000 /$ laboreal. 11413

ISSN: 1646-5237

\section{Editora}

Universidade do Porto

\section{Refêrencia eletrónica}

Graça Druck e Tânia Franco, «A Terceirização no Brasil : velho e novo fenômeno », Laboreal [Online], Volume $4 \mathrm{~N}^{0} 2$ | 2008, posto online no dia 01 dezembro 2008, consultado o 10 outubro 2019. URL : http://journals.openedition.org/laboreal/11413; DOI : 10.4000/laboreal.11413

Este documento foi criado de forma automática no dia 10 outubro 2019.

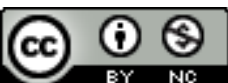

Laboreal está licenciado com uma Licença Creative Commons - Atribuição-NãoComercial 4.0 Internacional. 


\title{
A Terceirização no Brasil : velho e novo fenômeno
}

\author{
La subcontratación em Brasil : viejo e nuevo fenómeno \\ La sous-traitance au Brésil : vieux et nouveau phénomène \\ Service outsourcing in Brazil : old and new phenomenon
}

\section{Graça Druck e Tânia Franco}

\section{NOTA DO EDITOR}

Manuscrito recebido em : Julho/2008

Aceite após peritagem em : Novembro/2008

\section{NOTA DO AUTOR}

Uma versão modificada deste artigo foi publicada na Revista Latinoamericana de Estudios del Trabajo, v.13, p. 97 120, 2008, (Associação Latinoamericana de Estudos do Trabalho).

1 O objetivo desse artigo é discutir a terceirização hoje no Brasil. Optou-se por fazer o seguinte percurso: na primeira parte apresenta-se uma síntese das concepções da terceirização, suas novas modalidades e as principais implicações reveladas por um conjunto de pesquisas desenvolvidas na ultima década no país. Na segunda parte, expõe-se algumas das tendências do processo de terceirização reveladas por pesquisa recente realizada na indústria petroquímica da Bahia. Primeiramente, é necessario situar o fenômeno da terceirização no contexto das transformações no mundo do trabalho das últimas décadas, marcadas centralmente pela flexibilização (flexibilisation) e precarização (précarisation), compreendidas como novas estratégias de dominação do trabalho. Processos de caráter mundial, mas que apresentam especificidades em cada país, e é sob a ótica dessas particularidades tratadas pela 
literatura que se pretende abordar a temática. A “acumulação flexível” (Harvey, 1992) identifica uma nova fase do desenvolvimento capitalista, marcada pela hegemonia da lógica financeira, que subsume a lógica produtiva do capital. No âmbito das políticas de gestão do trabalho isso implica na implementação de mudanças inspiradas no toyotismo, cujo objetivo principal é a racionalização do uso da força de trabalho, visando ganhos de produtividade e redução de custos, que tem na flexibilização, em suas várias modalidades, a sustentação básica.

2 No Brasil essa transição para um novo padrão de gestão do trabalho, em resposta à crise do fordismo, começa no início dos anos 1980, ainda que localizadamente em algumas indústrias dinâmicas. Mas a generalização do toyotismo, no quadro do processo de reestruturação produtiva, vai ocorrer nos anos 1990, em decorrência da implementação das políticas neoliberais no país e da inserção do Brasil na globalização da economia.

Trata-se assim de um novo momento, seja no campo histórico mais geral, de um novo padrão de desenvolvimento do capitalismo, seja no âmbito das novas práticas de organização e gestão do trabalho, no interior das quais encontra-se a terceirização como uma das principais. Parte-se, portanto, de uma consideração central: a flexibilização do trabalho é um fenômeno novo, dadas a dimensão, a amplitude e a qualidade adquiridas num quadro de mundialização, de reestruturação produtiva e de implementação de políticas neoliberais. Tal consideração é evidenciada na produção da sociologia do trabalho, quando discute, por exemplo, o novo paradigma produtivo, os novos padrões de gestão/organização do trabalho inseridos no debate sobre o "pósfordismo" ou "neo fordismo"; os novos conteúdos do trabalho, as novas institucionalidades, o novo trabalhador, as novas formas de alienação do trabalho, o novo capitalismo flexível, etc. (Druck, 2005).

4 O atual processo de precarização do trabalho tem um caráter novo, mesmo admitindo que sempre houve trabalho precário no capitalismo, sobretudo no trabalho feminino (Hirata, 1997), mas trata-se de levar em conta as recentes metamorfoses do trabalho (Antunes, 1995), que metamorfosearam também a precariedade, que passa a ter um lugar estratégico e central na lógica da dominação capitalista, se institucionalizando em todo lugar e em todas as regiões do mundo, tantos nos países desenvolvidos e centrais, como em países como o Brasil.

5 É nessa mesma perspectiva que se inscreve o debate sobre a terceirização. Por isso concorda-se com Araújo (2001), quando afirma :

\begin{abstract}
A atualidade, entretanto, imprime à terceirização determinados atributos, ao ponto de se poder afirmar, sem exageros, tratar-se de um fenômeno novo. De peça acessória, periférica, complementar na arquitetura produtiva, ela se transforma em elemento central, em condição de flexibilidade, portanto, fundamental do ponto de vista da produtividade e da competitividade das empresas. Segundo documento do Sindicato dos Metalúrgicos do ABC (1993), o que marca a terceirização atual é o ritmo veloz com que tem sido introduzida, a sua abrangência e o fato de estar invadindo a própria cadeia produtiva (Araújo, 2001, p. 56).
\end{abstract}

6 Conclusão que é confirmada pelas pesquisas realizadas sobre a terceirização em suas várias modalidades, demonstrando-a, no plano empírico, como um fenômeno novo, desde os estudos pioneiros sobre o tema no início dos anos 1990 (Borges \& Druck, 1993 ; Druck \& Franco, 1997 ; Druck, 1999). 
7 Nessa medida, a terceirização é uma das principais formas ou dimensões da flexibilização do trabalho, pois ela consegue reunir e sintetizar o grau de liberdade que o capital dispõe para gerir e, desta forma, dominar a força de trabalho. Liberdade que é verificavél através da flexibilização dos contratos e, principalmente da transferência de responsabilidade de gestão e de custos trabalhistas para um “ terceiro ». Uma prática de gestão que encontra respaldo em vários aspectos e instrumentos que limitam a regulação do mercado de trabalho, a exemplo das mudanças na legislação trabalhista, cuja flexibilização ocorre no sentido de fortalecer a liberdade de ação empresarial, principalmente no que tange às perdas de direitos dos trabalhadores.

\section{Alguns tópicos da discussão conceitual da terceirização}

debate acerca do conceito de terceirização deve ser iniciado pela origem do próprio termo, cuja especificidade revela a palavra como criação brasileira. É o que mostra Carelli (2003), quando compara as diferentes denominações em todo o mundo[ $\left.{ }^{1}\right]$ e faz referência ao sentido literal da palavra que, por sua vez, desvenda o real conteúdo da prática, isto é, o repasse ou a transferência de uma atividade a um "terceiro ", a um “ outro ", que deve(ria) se responsabilizar pela relação empregatícia e, portanto, pelos encargos e direitos trabalhistas. Essa transferência é realizada por um " primeiro ». A partir daí, pergunta Carelli (2003), quem seria o segundo?

Pode-se acrescentar a essas considerações, numa mesma perspectiva, a palavra “ terceiros ». Esse termo carrega uma conotação que indica uma posição periférica e, no quadro dos processos de terceirização nos mais diversos setores, aponta para uma (des)qualificação em geral mais baixa, para uma condição mais precária, menos central e de subordinação aos “ primeiros »[2].

Dentre as diversas definições de terceirização cujos principais aportes vêm das áreas de administração, economia e sociologia, ou até mesmo dos inúmeros “manuais » elaborados por consultores de empresas (que orientam sobre como terceirizar sem se arriscar junto à legislação em vigor) constata-se que, embora os referenciais de análise sejam muito diferentes, há elementos comuns nos conceitos utilizados, como a idéia de “ repasse ", de " transferência ", de " especialização » e de " flexibilização ".

11 As definições apresentadas pelos apologistas da terceirização se constituem essencialmente numa justificativa para a sua aplicação, pois a defendem como um instrumento de focalização, isto é, a empresa deve se concentrar naquilo que é especialista, na sua atividade central e nuclear, ou naquilo que ela tem competência maior para fazer, e transferir as demais atividades para terceiros, cuja especialização trará melhores resultados em termos de redução de custos e produtividade. É interessante observar que neste quadro de definição - na perspectiva empresarial fala-se em atividade, em negócios, em produção, etc mas não se fala jamais em trabalho e em trabalhadores, que são exatamente os sujeitos principais que sustentarão as atividades, os negócios e a produção, "transferida ", " externalizada ", isto é, terceirizada. Para alguns autores, a terceirização é uma técnica administrativa “...que possibilita o estabelecimento de um processo gerenciado de transferência, a terceiros, das atividades acessórias e de apoio ao escopo das empresas que é a sua atividade-fim, 
permitindo a estas se concentrarem no seu negócio, ou seja, no objetivo final» (Queiroz, 1998, p. 53)

12 No campo dos estudos acadêmicos e, portanto, numa outra perspectiva de abordagem, a terceirização tem sido analisada como parte do novo padrão de organização do trabalho inspirado no toyotismo. Druck (1999) encontrou na literatura examinada à época, duas linhas de análise: uma que tem como referência o paradigma da "especialização flexível» (Piore \& Sabel, 1984), cujos estudos ressaltam a parceria interempresas, a flexibilidade produtiva como fator de incentivo às micro e pequenas empresas (Gitahy, 1994 ; Gitahy, Rabelo \& Costa, 1989), destacando os estudos de caso que demonstram a “boa » ou "verdadeira " terceirização. E numa outra linha, situa-se a maioria das análises que, a partir de estudos empíricos, demonstram a terceirização como política de gestão flexível do trabalho que tem levado, invariavelmente, à precarização das condições de trabalho, do emprego e da saúde (Ruas, 1993 ; Abreu \& Sorj, 1993 ; Borges \& Druck, 1993 ; Franco, Druck, Borges \& Franco, 1994), ao tempo em que as relações interempresas - contrantes e contratadas - têm sido de subordinação dessas últimas, que, pressionadas pela intensa concorrência, se utilizam das mais diversas formas de precariedade do trabalho (sem contratos, baixos salários, jornadas extensas, etc) para garantir a sua inserção no mercado.

Os estudos mais recentes, que refletem sobre a experiência transcorrida da (nova) terceirização dos anos 1990, demonstram cada vez mais a associação entre terceirização e precarização do trabalho, com destaque para as novas formas de terceirização, a exemplo das cooperativas. (Carelli, 2002 ; Lima, 1997, 2002, 2004 ; Piccinini, 2004 ; Krein, Gimenez \& Biavaschi, 2003).

Do lado dos consultores de empresas, alerta-se sobre os limites da " cega » redução de custos, como único objetivo da terceirização, e a possibilidade de perdas no médio e longo prazos.

15 Nesta perspectiva é interessante destacar a análise de Rezende (cit in Araújo, 2001), que, embora reconheça a predominância da terceirização como elemento fundamental da produção flexível, considera que, em certas situações pode ser necessário "primeirizar", ou seja, fazer retornar à empresa atividades terceirizadas. Caso ilustrativo dessa possibilidade foi a Caraiba Metais $\left[{ }^{3}\right]$ na Bahia, que optou por “primeirizar " setores de manutenção elétrica, informática, etc, em razão de custos altos com a terceirização e também pela maior frequência de acidentes de trabalho com terceiros.

\section{As velhas e novas modalidades da terceirização}

O debate conceitual se explicita ainda mais pelos estudos empíricos realizados nos últimos anos, que revelam as novas modalidades da terceirização. Druck (1999) encontrou na literarura e em pesquisa realizada na indústria petroquímica da Bahia em 1995 , os seguintes tipos de terceirização : i) trabalho doméstico ou trabalho domiciliar subcontratação de trabalhadores autônomos em geral, sem contrato formal, prática mais recorrente nas empresas de setores mais tradicionais da indústria; ii) redes de empresas fornecedoras de componentes e peças (tipica da indústria automobilistica); iii) subcontratação de serviços de apoio e periféricos ; iv) subcontratação de empresas ou trabalhadores autônomos em áreas produtivas e nucleares (manutenção) e v) quarteirização, empresas contratadas para gerir os contratos com as terceiras, 
caracterizando a cascata de subcontratação. Os dois últimos casos, caracterizavam na época o que havia de novo na terceirização, pois deixava de ser uma prática de “ focalização » no núcleo da atividade da empresa e passava, já naquele momento, a se difundir para todas as áreas da empresa, principalmente em setores chaves e nucleares, a exemplo do trabalho de manutenção na indústria, processo que se confirmou e se expandiu até a atualidade.

Nos últimos 15 anos, observou-se um forte crescimento da terceirização em todas as direções. Primeiro, a sua disseminação no setor público e nas empresas estatais, explicada fortemente pelas políticas neoliberais adotadas pelos sucessivos governos que, em nome do superávit fiscal recomendado pelo Fundo Monetário Internacional, suspenderam concursos públicos e buscaram sanar a necessidade de servidores através da terceirização em várias modalidades : contratação de estagiários (principalmente nas empresas estatais, nos bancos públicos) ; cooperativas, particularmente na área de saúde e a externalização ou transferência de serviços públicos para o setor privado.

Neste caso tem sido fundamental o papel do Ministério Público do Trabalho que, além da investigação e denúncia, tem instado o Estado a redefinir as relações estabelecidas com o processo de terceirização. O Procurador-chefe da Procuradoria Regional do Trabalho da $10^{\mathrm{a}}$ Região Distrito Federal e Tocantins, Dr. Ronaldo Curado Fleury, dá o seu testemunho:

19 A óbvia escassez de servidores públicos foi sanada com a contratação de empregados por meio de empresas interpostas, erroneamente chamada de terceirização, ou seja, promoveu-se a contratação de empresas que colocam à disposição dos entes públicos trabalhadores para a realização das tarefas para as quais não há servidores. Assim foi feito até com cooperativas de locação de mão-de-obra, organismos internacionais e organizações sociais de interesse público o chamado terceiro setor.

\section{(...) nossas investigações têm demonstrado que os órgãos públicos tomadores dos serviços indicam às empresas locadoras de mão-de-obra quais trabalhadores querem que sejam contratados, em flagrante desrespeito aos princípios constitucionais da impessoalidade e moralidade. (...)}

20 A União, reconhecendo as irregularidades apontadas, está, na medida em que instada, se adequando e substituindo os terceirizados por servidores concursados, como está ocorrendo em relação aos convênios de cooperação internacional, da mesma forma que algumas empresas públicas do Distrito Federal, como exemplificam o Metrô e a Caesb, que firmaram Termos de Ajustamento de Conduta visando substituir a mãode-obra irregularmente contratada por empregados públicos admitidos após processo seletivo público externo. (Fleury, 2005, p. 1 e 2).

21 Em segundo lugar, no setor privado, a terceirização, além de atingir as áreas de produção e nucleares, se expandiu para áreas que, até início dos anos 1990, ainda permaneciam sob responsabilidade da empresa, como é o caso de segurança e medicina do trabalho, dois setores chaves para o acompanhamento dos riscos de acidentes e das condições de saúde dos trabalhadores, agora explicitamente considerados como “ serviços periféricos".

E, por fim, surgiram novas modalidades de terceirização, podendo-se elencar três mais importantes : i) o trabalho a domicílio ; ii) as “empresas filhotes » ou as empresas do “ eu sozinho » e iii) as cooperativas. 
23 No plano internacional, o trabalho a domicílio sofre transformações importantes, deixando de ser apenas utilizado pelas indústrias tradicionais para se tornar “(...) o centro das novas estratégias de gestão da força de trabalho", que ultrapassa as fronteiras nacionais, pois passa a ser parte da flexibilização necessária às cadeias produtivas internacionais (Lavinas, Sorj, Linhares \& Jorge, 1998, p. 1,2). O exemplo mais claro desse processo é o teletrabalho[ $\left.{ }^{4}\right]$, que conforme os autores, são "ocupações que absorvem trabalhadores qualificados, com capacidade de geração de rendimentos elevados e capazes de introduzir contratualidades inovadoras entre clientes e fornecedores, sejam eles indivíduos ou micro-empresários. » (Lavinas et al., 1998, p. 4)

No entanto, no Brasil, embora as pesquisas venham constatando inovações no trabalho a domicílio, principalmente no setor de informática e em alguns casos específicos de empresas[5], Lavinas et al. (1998) mostram, através de análise de tabulações especiais da PNAD para o ano de 1995, que dos trabalhadores que realizavam atividades em casa, $50 \%$ trabalhavam em serviços de reparação, pessoais, serviços domiciliares ou de diversões ; 12 \% trabalhavam na indústria de transformação tradicional e apenas $1 \%$ em indústrias mais modernas. Ou seja, um trabalho a domícilio que ainda predomina nos setores mais tradicionais e em condições precárias, constituído em sua maioria por mulheres (78,5\%).

No segundo caso, explicita-se o crescimento do assalariamento disfarçado, pois trata-se de um processo de contratação de trabalhadores que são pressionados a redefinirem a sua personalidade jurídica, ou seja, registram uma empresa em seu nome, assumindo todos os encargos por isso, e se transformam assim numa empresa individual terceirizada. A motivação para tal modalidade é óbvia, abole-se a relação empregatícia, bem como todos os seus custos econômicos, sociais e politicos, ou seja, todos os direitos trabalhistas, passando o novo trabalhador-empresa a ser tratado de "igual para igual». Esta modalidade explica o rápido crescimento de micro empresas no país, mesmo numa conjuntura crítica de mercado. A terceira e mais importante nova modalidade de terceirização são as cooperativas, reveladas pelas pesquisas em todas atividades e setores da produção e do trabalho e em todas as regiões do país.

Borges e Druck (2002) analisando os dados da Pesquisa Terceirização na Bahia 2000[ [6], indicavam que as cooperativas eram o destaque das novas formas de terceirização, pois eram utilizadas por $21 \%$ de todas as empresas entrevistadas, por $27 \%$ das empresas do setor industrial e por $40 \%$ da indústria petroquímica da Bahia.

o que diferencia as cooperativas das modalidades encontradas anteriormente é a definição formal/legal que, coberta por legislação específica, garante às grandes empresas contratantes se utilizarem de um contrato que as dispensa de todos os custos associados aos direitos garantidos pelo assalariamento formal. Ou seja, os trabalhadores são cooperativados e, nesta condição, não são assalariados, o que lhes retira a proteção social do Estado já que, teoricamente, eles estariam se "auto-gerindo" e assim se "autoprotegendo", conforme Borges e Druck (2002).

Krein, Gimenez e Biavashi (2003) em pesquisa realizada pelo CESIT/Unicamp, constatam a expansão das cooperativas no Brasil, especialmente as cooperativas de trabalho, operando como intermediadoras de mão-de-obra. Neste estudo, tomando por base uma tipologia construida por Perius (1996), indicam a diferença entre as cooperativas de trabalho e as cooperativas de mão-de-obra. As primeiras são definidas como as 
“(...) que dispõem de capital, equipamentos e instalações industriais próprias, produzindo em suas instalações bens e serviços, sem depender de um tomador específico. Relacionam-se com o mercado para vender bens ou serviços produzidos : as mercadorias(...) ». (Krein, Gimenez \& Biavashi, 2003, p. 9).

As cooperativas de mão-de-obra são as :

que operam nas instalações de outras empresas que se constituem as tomadoras de serviços. Não se relacionam no mercado, pois não produzem bens e serviços próprios, senão que deslocam a força de trabalho de seus "cooperativados" para os tomadores, beneficiários diretos de seus serviços. Ex : cooperativas de catadores e de reciclagem de lixo, de jardineiros, de safristas, etc. É sobre esse tipo que residem os maiores problemas. Têm, na realidade, operado como intermediadoras de mão-de-obra. » (Krein, Gimenez \& Biavashi, 2003, p. 9)

São estas últimas as que mais crescem no Brasil. Entre 1998 e 2001 saltaram de 1.334 para 2.391[?]. Paralelo a esse crescimento, aumentam as denúncias de cooperativas fraudulentas $\left.{ }^{8}\right]$, com destacada atuação do Ministério Publico do Trabalho. Uma modificação do art. 442 da CLT, através da Lei 8.949/94, estabeleceu que “ (...) qualquer que seja o tipo de cooperativa, não existe vínculo empregatício entre ela e seus associados". Definição que deu margem ao uso e abuso das cooperativas pelas empresas, pois se abriu uma possibilidade legal para se desresponsabilizarem dos direitos trabalhistas e encargos sociais, já que :

Muitos trabalhadores perderam o status formal de empregados, passando a "sócios" de cooperativas. Como "sócios", não têm suas carteiras de trabalho registradas, não lhes sendo assegurados básicos direitos como: férias, 13ํㅜㅇ salário, descanso semanal remunerado, FGTS, previdência social. Por outro lado, deixam de pertencer à categoria profissional original. Com a supressão desse vínculo social básico, vantagens decorrentes de negociações coletivas ou sentenças normativas não mais lhes são alcançadas. Com esse deslocamento, além da perda da condição de sujeito empregado e dos direitos decorrentes, no limite é a própria organização dos trabalhadores que se fragiliza. (Krein, Gimenez \& Biavashi, 2003, p. 12)

31 Vários são os estudos que demonstram esse evidente processo de precarização do trabalho. Piccinini (2004) estudando as cooperativas no Rio Grande do Sul, revela que, para os dirigentes das cooperativas, essas são a melhor forma de flexibilização, vista como positiva, já que "(...) é possivel adequar os trabalhadores às necessidades do mercado ", através de horários flexíveis, pro-labore flexível, contratos flexíveis com as empresas. Para um dos casos estudados, a direção da cooperativa considera que :

(...) a terceirização, através das cooperativas, é a melhor alternativa para o amadurecimento das relações trabalhistas no Brasil, sem as restrições atuais da CLT (Consolidação das Leis Trabalhistas), pois o trabalhador passa a se autogerir, sendo, portanto, mais responsável e produtivo, consciente de que o seu ganho depende diretamente do seu empenho. (Piccinini, 2004, p. 89)

Já para os cooperativados, a cooperativa foi a alternativa que encontraram para o desemprego, além de declararem que preferiam uma relação de emprego assalariado, sob a proteção da CLT. 

importância que as cooperativas " pragmáticas " $\left[^{\circ}\right]$ adquiriram no contexto da guerra fiscal entre os governos estaduais e municipais, pois incluíam no “(...) 'pacote' de incentivos oferecidos às empresas que se instalassem em seus territórios a terceirização industrial em cooperativas de produção organizadas por instituições governamentais. », (Lima, 2004, p. 51). Os setores industriais mais favorecidos são os que utilizam trabalho intensivo, como têxtil, vestuário e calçados, embora essa desconcentração industrial também atinja setores como bebidas, siderurgia, alimentos processados, bicicletas, etc. As empresas alinham-se na busca de baixos salários, isenções fiscais e fexibilidade de contratos, configurando uma estratégia na qual a terceirização via cooperativas tem sido a regra. subordinadas à hierarquia, organização e demandas da empresa contratante, numa clara relação de dependência, o que implica numa condição de contrôle e não de autonomia do trabalhadorcooperado. Na realidade, o trabalhador perde a sua condição de assalariado e os direitos decorrentes, além de ficar a mercê das demandas da empresa contratante, forçado a cumprir prazos muito curtos e intensificando sua jornada de trabalho.

35 No setor têxtil do Ceará, a remuneração média dos cooperados raramente ultrapassa 1,5 salários mínimos. Remunerações tão baixas através das cooperativas implicam numa brutal redução de custos, a tal ponto, que hoje permitem competir com a produção de camisetas da China, cujo custo era, até então, o mais baixo do mundo. Destaca-se o caso de um dos grandes grupos estudados (originário de Taiwan), cuja produção é terceirizada através de 20 cooperativas de costureiras, reunindo 1.600 trabalhadoras, com financiamento do Banco do Nordeste e do Governo do Estado. Os estatutos e regimentos das cooperativas são " sugeridos » pela empresa contratante, que define as normas e regras de admissão, demissão, disciplina, hierarquia, remuneração e férias. Ou seja, não só as cooperativas estão completamente subordinadas às empresas, mas a gestão do trabalho se dá efetivamente pela contratante, caracterizando, em suma, o assalariamento disfarçado. Este fato levou a empresa de Taiwan a ser investigada pela procuradoria do Estado. (Lima, 1997 ; Lavinas et al., 1998).

$\mathrm{Na}$ realidade, conforme demonstrado pelas pesquisas, pode-se considerar as cooperativas como a forma de terceirização mais perversa que se difundiu durante a década, já que precariza o trabalho de forma legal coberta pela legislação - e alimenta uma ilusão para aqueles trabalhadores que acreditam ser a cooperativa uma alternativa de autogestão e de um trabalho solidário, muito além de uma alternativa ao desemprego.

\section{Uma década de terceirização : principais tendências em empresas industriais na Região Metropolitana de Salvador/BA}

37 Tendo como ponto de partida um estudo realizado entre 1993 e 1995 sobre a terceirização e condições de trabalho em 44 empresas contratantes no complexo de indústrias na Região Metropolitana de Salvador/Bahia (RMS/BA), realizou-se uma nova pesquisa entre $2004 / 05\left[{ }^{10}\right]$, buscando-se verificar mudanças e permanências no 
processo de terceirização ao longo de uma década, numa amostra atualizada destas empresas contratantes[1]].

Trata-se de 19 empresas industriais $\left[{ }^{12}\right]$ químicas, petroquímicas, de petróleo e siderúrgicas 11 das quais iniciaram operação na RMS durante a década de 1970 e uma em período anterior. As demais foram implantadas entre as décadas de 1980 e 1990. Entre 1993 e 2004, 15 destas empresas passaram por um ou mais processos de reestruturação patrimonial, envolvendo fusões, incorporações, mudanças acionárias, etc. Estas re-estruturações são mais intensas entre 2002 e 2004, e no seu bojo ocorreram mudanças na configuração e formas de gestão e organização do trabalho, incluindo programas de qualidade total, re-estruturações administrativas, práticas participativas, terceirização, etc. Mudanças conduzindo à flexibilização do trabalho, com nítidas repercussões na absorção de trabalhadores pelas empresas.

No tocante ao contingente de Empregados, a pesquisa anterior (1993-95) confirmou a característica típica destes ramos industriais, qual seja, a sua baixa capacidade de absorção de trabalhadores, dado o elevado patamar tecnológico, crescentemente automatizado. Em 1993-95, foi encontrada uma média de 353 empregados por empresa. Uma década depois, constata-se a mesma média de empregados por empresa, com dois importantes aspectos distintivos: i) nenhuma delas apresenta mais de 2 mil empregados no quadro permanente, como outrora ;ii) as empresas industriais situadas no Pólo Petroquímico de Camaçari - mais arrojadas em termos de reestruturações ao longo da década e mais avançadas no enxugamento e terceirização de trabalhadores apresentam uma média inferior de 282 empregados/empresa.

\section{As principais tendências : mudanças e permanências no processo de terceirização}

Observando a evolução da terceirização neste conjunto de empresas[13], é possível constatar traços de continuidade neste processo, desde o final da década de $1980:$ i) o traço característico destes ramos industriais de serem poupadores de mão-de-obra ; ii) o processo de demissões atingindo os mais diversos tipos de profissionais; iii) o enxugamento e redução de níveis hierárquicos com a redução do emprego; iv) a crescente "externalização" de atividades, transferidas para 'terceiros' e realizadas, predominantemente, nas próprias dependências das contratantes.

Desde a década de 1990 e início dos anos 2000, ocorre a acentuação das tendências anteriormente referidas, com novas nuances e fenômenos sociais que merecem destaque : i) a persistência do processo de redução de empregados "permanentes" das empresas ; ii) a difusão e generalização da terceirização nas diversas áreas de atividade das empresas contratantes; iii) um acentuado grau de terceirização das empresas contratantes (crescente proporção de trabalhador terceirizado/trabalhador do quadro permanente; iv) a ampliação do segmento de terceirizados sob modalidades variadas de contratação ; v) a diversificação dos tipos de contratação de trabalhadores que se distanciam do âmbito de regulação da legislação trabalhista; vi) indícios de precarização das relações de trabalho (marcante diferença do custo médio do trabalhador empregado do quadro permanente em relação ao custo médio do trabalhador terceirizado); vii) a persistência das reclamações trabalhistas, a despeito do declarado controle e cumprimento da legislação por parte das empresas. 

empregados do quadro permanente ao longo da década de 1990 e início dos anos 2000, como política de gestão das empresas. Focalizando 5 empresas que forneceram a série histórica completa, constata-se uma redução contínua entre 1993 e 2001, com oscilação e leve aumento em 2002 e 2003 do número de empregados do quadro permanente. Contudo, a resultante é a redução de 1.072 empregados, ou seja, um corte de $32,9 \%$ do emprego permanente. Se observarmos este fenômeno por grandes áreas das empresas, pode-se constatar uma redução na Área Administrativo-financeira de 50,6\% dos empregos administrativos em relação ao ano de 1993 (incluindo todas as sub-áreas, com a extinção de algumas, a exemplo de RH). Neste mesmo período, na da Área Técnica, houve uma redução de $28,8 \%$ do quadro (atingindo mais fortemente os empregados da manutenção, operação/ produção e laboratório. Na verdade, nesta última década, manteve-se a redução que já vinha ocorrendo predominantemente na área Técnica desde os anos 1980 e acentuou-se o enxugamento na área Administrativa.

Há dois movimentos simultâneos no processo de terceirização na década de $1990 \mathrm{e}$ início dos anos 2000 que vale ressaltar :

I. ampliação e difusão da terceirização na maior parte das sub-áreas de atividades administrativas e técnicas dentro das empresas, isto é, expande-se o leque de tipos/áreas e subáreas de atividades dentro da empresa executados por trabalhadores terceirizados ;

II. crescem as proporções de terceirizados na composição da mão de obra da empresa,ou seja, o grau de terceirização das empresas.

A pesquisa revela um alto grau de terceirização das empresas contratantes (crescente proporção de trabalhador terceirizado/trabalhador permanente). Considerando um sub-conjunto de dez empresas, apenas 36,3 \% trabalhadores são Empregados do Quadro Permanente, sendo o restante terceirizado. Convém salientar que nenhuma destas empresas encontravase em parada para manutenção. Estas empresas se diferenciam quanto ao grau de terceirização: apenas duas delas têm mais de metade dos trabalhadores sob a modalidade de empregados do "quadro permanente". As demais, com maioria de trabalhadores terceirizados na composição de sua força de trabalho, apresentam entre $49,1 \%$ e até $28,5 \%$ apenas de trabalhadores do quadro permanente.

O processo de terceirização ocorre com a diversificação das formas de contratação. Os principais tipos de contratados detectados envolvem desde aquelas formas mais típicas da década de 1980, tais como :

I. Empresa Prestadora de Serviços Especializados Não Industrial ;

II. Outra Empresa Industrial ; e

III. Locadora de Mão-de-Obra ; até os tipos emergentes na pesquisa 2003-05, tais como :

IV. Cooperativas;

V. Prestador de Serviços/Firma Individual (empresa filhote) e

VI. ONG/Entidades Sem Fins Lucrativos.

Esta diversificação dos tipos de contratação de trabalhadores revela um distanciamento dos contratantes do âmbito de regulação social da legislação trabalhista. Dentre as 19 empresas, 17 declararam contratar cooperativas, representando em torno de $89,5 \%$ das empresas respondentes. 15 empresas afirmam que as cooperativas por elas contratadas prestam serviços em outras empresas; 2 empresas afirmam que as cooperativas contratadas não prestam serviços em outras empresas e 7 empresas indicam, 
explicitamente, o uso de extrabalhadores do quadro permanente nas cooperativas contratadas.

A pesquisa aponta para a precarização das relações de trabalho no processo de terceirização do trabalho. No tocante à questão salarial, vale destacar, ainda que a partir de indicadores pontuais e restritos a um conjunto de 6 empresas, a significativa diferença dos custos médios unitários entre os Trabalhadores do Quadro Permanente e os Terceirizados nas empresas contratantes. Pode-se constatar que estes últimos "valem", entre 5 e 1,4 vezes menos do que o empregado do quadro permanente.

Diante de tais considerações, não deve causar surpresa o fato da pesquisa apontar para a persistência das reclamações trabalhistas tanto por parte dos Empregados do Quadro Permanente, quanto por parte dos Terceirizados.

Os tipos de reclamações mais freqüentes dos empregados permanentes do quadro, no ano de 2003, foram: i) Equiparação salarial/diferença salarial; ii) valores do FGTS (multa, expurgos, planos) ; iii) Horas extras ; iv) Danos morais e materiais ; v) Plano de Benefício Complementar, dentre outros. Todas estas reiteram a importância das questões salariais e de jornada de trabalho (Horas Extras) para os Empregados do Quadro Permanente das empresas, indicando, provavelmente, a precarização das condições de trabalho.

Em relação aos trabalhadores contratados, 16 das 19 empresas respondentes afirmaram ter sofrido reclamações trabalhistas. Dentre os tipos de reclamações ajuizadas em 2003, destacam-se : i) 213 ações de Responsabilidade subsidiária ou solidária; ii) 5 ações de Reconhecimento de vínculo.

\section{Segurança e saúde no trabalho}

51 No bojo do processo de terceirização nas décadas de 1990 e início de 2000, juntamente com as alterações patrimoniais, ocorrem mudanças nas formas de organização e gestão do trabalho que atingem os setores de segurança industrial e saúde, conforme também demonstrado em outras pesquisas.

Dentre as diversas mudanças e suas conseqüências, pode-se destacar: i) a crescente externalização dos serviços médicos das empresas; ii) os avanços nas proposições formais de programas de prevenção e melhoria dos aspectos de saúde, segurança e meio ambiente, bem como nas certificações correlatas. No caso das empresas do Pólo Petroquímico de Camaçari, deve-se mencionar a re-estruturação do PAME Plano de Assistência Médica em Emergência; e iii) maiores dificuldades para a obtenção dos dados referentes aos acidentes de trabalho e adoecimentos de trabalhadores permanentes e/ou terceirizados, dentre outros. Conforme previmos em pesquisas anteriores, a terceirização lança um manto de invisibilidade sobre o mundo real do trabalho, bem como sobre os problemas de saúde relacionados ao trabalho, principalmente no que concerne aos trabalhadores terceirizados $\left.{ }^{14}\right]$.

53 Os problemas gerais de saúde mais freqüentes que afetam os empregados "permanentes" e os trabalhadores terceirizados, referidos pelas empresas, são: i) Doenças do Aparelho Respiratório; ii) Distúrbios e Lesões Ósteo-Musculares; iii) Distúrbios do Aparelho Digestivo e iv) Distúrbios Cárdio-Vasculares. Em relação aos terceirizados especificamente, vale ressaltar a importância dos Traumatismos e 
Queimaduras; das Lesões Dermatológicas, que, além dos problemas respiratórios, indicam uma maior exposição aos riscos e às condições inseguras de trabalho.

Por fim, salienta-se que a categoria Distúrbios e Lesões Ósteo-musculares (especificamente LER/DORT) foi declarada como o $2^{\circ}$. problema mais freqüente de saúde entre os trabalhadores empregados ou terceirizados - em contraste com a pesquisa anterior de 1993-95 (quando foi referido como 5‥ problema de saúde mais freqüente).

\section{Os efeitos perversos da terceirização}

55 Nos estudos acadêmicos sobre a terceirização no Brasil, dentre os quais, os referidos anteriormente, a precarização é presença marcante invariavelmente. Druck (1999), em pesquisa no inicio dos anos 1990, concluiu sobre a quádrupla precarização do trabalho advinda do processo de terceirização : i) do emprego (e do mercado de trabalho), ii) das condições de trabalho (do processo de intensificação do trabalho e dos riscos), iii) da saúde do trabalhador (maior exposição aos acidentes e adoecimentos) e iv) dos sindicatos (pela fragmentação e pulverização das organizações sindical e seu enfraquecimento).

Nos últimos 15 anos, o crescimento da terceirização e suas novas modalidades confirmou essas implicações. As pesquisas têm evidenciado a amplificação em termos quantitativos e qualitativos, cujos recortes têm permitido aprofundar as evidências da precarização em cada campo estudado, a exemplo dos resultados da pesquisa na indústria petroquímica da Bahia, ainda em desenvolvimento, anteriormente comentados.

57 As análises sobre as mudanças no mercado de trabalho no país (Pochmann, 1998, 1999; Borges, 2003; Dedecca, 1998; entre outros) ressaltam o crescente processo de informalização no período e o aumento dos contratos precários (por tempo determinado, temporário, por empreita, sem carteira assinada, etc.), formas típicas encontradas com a terceirização. Alerta-se para a crescente terciarização - expansão dos serviços - que, no caso da terceirização na indústria, distorce e superestima as informações, à medida que as " prestadoras de serviços » ou terceirizadas continuam desenvolvendo um trabalho industrial, embora sejam classificadas no setor terciário.

Os estudos de Carelli $(2002,2003)$ no campo do Direito do Trabalho são exemplares para provar a ilegalidade da terceirização enquanto intermediação de mão-de-obra, proibida por lei, e de indicar a perversidade das cooperativas fraudulentas e o papel do Ministério Público do Trabalho na averiguação e exigência de redefinição das relações precárias e ilegais de trabalho. Além de explicitarem o desrespeito às leis, ou mesmo a fragilidade e ambiguidade destas, destacam, principalmente, a flexibilização/ fragilização da legislação trabalhista ocorrida nos anos 1990, ressaltando a importância de determinados atores, a exemplo do Ministério Público do Trabalho, cuja vontade política e autonomia frente ao Estado e aos governos podem garantir uma intervenção indispensável para mudar o cenário da precariedade do trabalho no país.

Cabe ressaltar no âmbito da legislação, a polêmica e debate interminável no campo da interpretação do direito acerca dos seguintes instrumentos legais. Em primeiro lugar, a antiga Lei (6.019) de 1974, que estabeleceu o contrato temporário de trabalho (para atender necessidades transitórias de substituição de pessoal regular), que continua 
sendo utilizada até hoje de forma abusiva, abrindo as portas para a terceirização. Em segundo lugar, mais recentemente, o Enunciado[ $\left.{ }^{15}\right] 331$ do TST, de 1993, decorrente do crescente número de casos julgados pelo Tribunal, que definiu, dentre outros itens, os seguintes :

I. A contratação de trabalhadores por empresa interposta é ilegal, formando-se o vínculo diretamente com o tomador dos serviços, salvo no caso de trabalho temporário... » e (...)

II. Não forma vínculo de emprego com o tomador a contratação de serviços de vigilância (Lei $\mathrm{n}^{\mathrm{Q}}$ 7.012/83), de conservação e limpeza, bem como a de serviços especializados ligados à atividade-meio do tomador, desde que inexistente a pessoalidade e a subordinação direta. (Carelli, 2003, p. 109). Freitas, 1996; Franco, 1997) até mais recentemente (Miranda, s.d.; Freitas, Souza, Machado \& Porto, 2001 ; Araújo, 2001 ; Amâncio \& Khouri, 2001 ; Souza \& Freitas, 2002 ; Grusenmeyer, 2007; Vidal-Gomel, Olry, Lanoe \& Jeanmougin, 2007), os resultados apontam para os seguintes aspectos e conclusões :

i. Os limites das estatísticas oficiais sobre acidentes de trabalho e doenças profissionais, devidos principalmente a subnotificação e sub-registro, motivo reforçado com a crescente terceirização, que produz a externalização dos riscos. Pois :

ii. "o processo de terceirização tem aumentado a invisibilidade dos acidentes e doenças ocupacionais e a desproteção dos trabalhadores vitimados, revelando ser não apenas um processo de transferência de atividades entre empresas e setores da economia, no bojo de uma nova divisão do trabalho, mas também uma transferência de riscos e de responsabilidades - sobre a segurança e saúde dos trabalhadores - das empresas petroquímicas para as subcontratadas". (Borges \& Franco, 1997, p. 106)

iii. a terceirização se constitui na principal prática de gestão do trabalho que cria e transfere os riscos para os trabalhadores, dada a instabilidade e rotatividade dos mesmos, além da falta de controle, segurança, treinamento e qualificação para os subcontratados internos e externos.

iv. Os acidentes fatais (com morte) ocorrem em sua imensa maioria com os trabalhadores terceirizados $\left[{ }^{[16}\right]$.

v. As Normas regulamentadoras (NR) de Segurança e Saúde no Trabalho não estão sendo cumpridas pelas empresas terceiras, a exemplo da inexistência : de Cipas, de SESMT (Serviço Especializado em Engenharia de Segurança e em Medicina do Trabalho), do PPRA (Programa de Prevenção de Riscos Ambientais); o PCMSO (Programa de Controle Médico de Saúde Ocupacional). Para todos esses casos, as NRs se referem explicitamente ao caso das terceiras e suas responsabilidades em garantir o cumprimento e aplicação desses programas. No entanto, as inspeções e pesquisas revelam o total descaso e descumprimento, assim como as precárias condições sanitárias e de higiene nos locais de trabalho para os terceirizados. (Miranda, s.d. ; Franco \& Afonso, 1997).

63 No que se refere aos efeitos explicitamente políticos da terceirização, destacam-se os seguintes aspectos : i) o processo de discriminação entre trabalhadores contratados e terceirizados, (Godinho, 2003; Miranda, s.d.) ; ii) a discriminação dos terceirizados 
realizada pela própria empresa, com espaços demarcados e áreas proibidas de serem frequentadas, sendo o trabalhador terceirizado, frequentemente, considerado um

“ incômodo estrangeiro ", cuja presença traz constrangimentos para a empresa (Araújo, 2001); iii) pulverização e enfraquecimento dos sindicatos, cuja representação é ameaçada pela crescente divisão entre as diversas categorias profissionais, cada uma com o seu sindicato, com atuações competitivas entre si[1"].

Efeitos perversos reafirmam a terceirização como uma das principais formas de flexibilização e precarização do trabalho, no sentido das novas políticas de dominação do capital e de alienação do trabalho.

\section{A Resistência e os Contra-poderes}

O processo de flexibilização e a precarização do trabalho reveladas pela subcontratação, apesar das relações de forças desfavoráveis aos trabalhadores, não consolidou um estado de precariedade e não estabeleceu um "consenso da flexibilidade" como única alternativa à crise do capitalismo. Prova disso são as diversas formas de resistência e de contra-poderes que têm feito recuar, mesmo que pontualmente, este processo.

Neste movimento, a defesa da saúde dos trabalhadores individual e coletiva - é uma das fontes mais radicais de contrapoderes ao imperialismo econômico da chamada "globalização". A resistência das vítimas dessa política econômica, quer seja do lado da saúde ou da exclusão social, começou a se manifestar com novas formas de mobilização social, dando visibilidade às contradições entre essa política e os direitos fundamentais : direito à saúde, direito à segurança econômica, direito à aposentadoria, direito à dignidade. (ThébaudMony \& Druck, 2007)

No caso do Brasil, vale destacar três exemplos que expressam a resistência ao processo de precarização do trabalho nos últimos anos. Em primeiro lugar, e a mais destacada delas, é a atuação do Ministério Público do Trabalho (MPT), cuja autonomia e independência, estabelecidas pela Constituição de 1988, têm permitido a realização de um incansável trabalho de fiscalização e denúncia das injustiças, da ilegalidade e do abuso de poder nas relações de trabalho. No que tange à subcontratação, a atuação do MPT tem obtido excelentes resultados, a exemplo do recuo no uso de cooperativas e ONGs, subcontratadas pelo Estado e por empresas públicas. Apoiado na (frágil) legislação, o MPT tem denunciado a ilegalidade desses contratos e exigido a substituição dos trabalhadores subcontratados por concursos públicos, o que tem se efetivado[ $\left.{ }^{18}\right]$. Em segundo lugar, a luta realizada conjuntamente por lideranças sindicais, fiscais do trabalho, profissionais do Ministério do Trabalho, trabalhadores adoecidos e familiares contra a precarização da saúde no trabalho, organizando-se nacionalmente para reagir às investidas de privatização dos órgãos de controle $\mathrm{e}$ pesquisa sobre acidentes de trabalho e doenças profissionais. Assim, destaca-se a atuação pela proibição do uso do amianto no Brasil e a campanha "caça benzeno". A Associação Brasileira de Expostos ao Amianto (ABREA), criada em 1995 e a Rede VirtualCidadã pelo Banimento do Amianto, constituída em 1994, são resultados de uma luta que avançou e popularizou, denunciando à sociedade brasileira, os malefícios do amianto, que tem levado trabalhadores à morte, ao adoecimento e tornados incapazes para o trabalho. A partir da atuação destas associações, 12 municípios brasileiros e cinco estados decretaram leis proibindo o uso do amianto. Além disso, hoje há, por 
parte de instituições públicas, inclusive do Ministério da Saúde, o reconhecimento da periculosidade do amianto, conforme portaria de 2006, que estabelece a vigilância, pelo Sistema Único de Saúde (SUS), dos trabalhadores expostos ao amianto.

Além desses atos, a ABREA e os sindicatos dirigem uma verdadeira guerra de ações penais e civis, exigindo a condenação das empresas que usam amianto e reivindicando a indenização e assistência à saúde aos trabalhadores adoecidos. Processos que têm sido acolhidos favoravelmente pelo Ministério Público do Trabalho, obtendo importantes ganhos para os trabalhadores atingidos pelas doenças provocadas pelo amianto[ $\left.{ }^{19}\right]$.

Em terceiro lugar, a luta dos sindicatos contra a subcontratação e a denúncia sobre o uso de cooperativas como intermediadoras de mão-de-obra. Embora numa situação de defensiva diante dos processos de reestruturação produtiva, os sindicatos têm manifestado a sua oposição à subcontratação, denunciando sistematicamente os prejuízos e as perdas sofridas pelos trabalhadores. Dentre as ações dos sindicatos, encontra-se a criação de departamentos responsáveis por acompanhar os terceirizados, a exemplo do Sindicato dos Químicos e Petroleiros da Bahia, cujo departamento de Empreiteiras [...] tem sua atenção voltada especialmente à luta dos terceirizados que trabalham em empresas do ramo químico e petroleiro. Desenvolve uma política de apoio aos terceirizados, tentando diminuir a exploração, principalmente daqueles que não têm sindicatos organizados. As atividades do setor são frequentemente realizadas em conjunto com outros setores como formação e mobilização. (Sindicato dos Químicos e Petroleiros, http://www.sind.org.br/index.asp, acesso em 30/04/2006).

71 Mais recentemente, a Central Única dos Trabalhadores - CUT anunciou a abertura de uma campanha nacional contra a subcontratação, em resposta ao Projeto de Lei (4330/2004), aprovado por unanimidade pela Comissão de Desenvolvimento Econômico, Indústria e Comércio da Câmara Federal em maio de 2006. Esse projeto propõe derrubar todas as frágeis limitações existentes à subcontratação em termos de legislação, a exemplo do Enunciado 331, que impede a subcontratação da atividade-fim da empresa, além de admitir a quarteirização e descartar qualquer vínculo empregatício entre os trabalhadores subcontratados e as empresas contratantes. Segundo a Secretaria Nacional de Organização da CUT, “... O principal objetivo em regulamentar as terceirizações no PL[Projeto de Lei] em questão é de proteger as empresas frente ao grande número de processos trabalhistas, transformando a relação emprego em uma relação comercial, portanto isenta de qualquer responsabilidade com os direitos dos trabalhadores." São novas formas de mobilização e novos atores políticos demonstrando que a vontade e a ação coletivas, através de associações da sociedade civil, de instituições do poder público e de organizações dos trabalhadores podem se constituir em contra-poderes e fazer recuar a precarização do trabalho, indicando que não é um processo irreversível. 


\section{BIBLIOGRAFIA}

Amâncio, V. \& Khouri, M. (2001). Efeitos da terceirização nas condições de segurança e saúde dos trabalhadores do setor elétrico do Ceará. In SINAIT - Sindicato Nacional dos Auditores Fiscais do Trabalho, A Flexibilização das Normas Trabalhistas e a Atuação dos Auditores Fiscais do Trabalho Resultado do Concurso do 19ํㅡㄹ ENAFIT (p. 10-26). Brasília : SINAIT.

Antunes, R. (1995). Adeus ao trabalho ? ensaio sobre as metamorfoses e a centralidade do mundo do trabalho. São Paulo : Cortez.

Araújo, A. (2001). Paradoxos da Modernização : Terceirização e Segurança dos Trabalhadores em uma Refinaria de Petróleo. Tese de Doutoramento, FIOCRUZ, Rio de Janeiro.

Borges, A. \& Druck, G. (1993). Crise global, terceirização e a exclusão no mundo do trabalho. Caderno CRH, 19, 22-45.

Borges, A. \& Druck, G. (2002). A Terceirização : Balanço de uma década. Caderno CRH, 37, 179-196. Borges, A. \& Franco, A. (1997). "Mudanças de Gestão : para além dos muros da fábrica”. In Tânia Franco (org.,) Trabalho, riscos industriais e meio ambiente : rumo ao desenvolvimento sustentável ? (p. 63-116). Salvador : EDUFBA.

Borges, A. (2003). Desestruturação do Mercado de Trabalho e Vulnerabilidade Social : a Região Metropolitana de Salvador na década de 90. Tese de Doutorado em Ciências Sociais, Faculdade de Filosofia e Ciências Humanas da Universidade Federal da Bahia, Salvador.

Campos, G. (2004). Cooperativas de Trabalho e Flexibilização Produtiva : quando "estar juntos" transforma-se em uma estratégia perversa de exclusão. Caderno CRH, 41, 269-280.

Carelli, R. (2002). Cooperativa de Mão-de-obra : manual contra a fraude. São Paulo : LTR.

Carelli, R. (2003). Terceirização e Intermediação de mão-de-obra : ruptura do sistema trabalhista, precarização do trabalho e exclusão social. Rio de Janeiro : Ed. Renovar.

Deddeca, C. (1998). Reorganização das relações de trabalho no Brasil. A flexibilidade é a única alternativa. In A. M. Carvalho Neto \& R. A. A. Carvalho (orgs.), Sindicalismo e negociação coletiva nos anos 90 (p.151-180). Belo Horizonte : IRT.

Druck , G . (2005). Flexibilização e Precarização do Trabalho - um estudo comparativo FrançaBrasil. Plano de estudos/Estágio Pos doutoral, Paris, Centre de Recherche sur Les Enjeux Contemporains em Santé Publique Universidade de Paris XIII/EHESS/INSERM - Paris - France. Druck, G. \& Franco, T. (1997). A degradação do trabalho e os riscos industrias no contexto da globalização, reestruturação produtiva

Druck, G. (1999). Terceirização : (Des)Fordizando a Fábrica - um estudo do Complexo Petroquímico da Bahia. São Paulo/Salvador : Boitempo/Edufba.

e das políticas neoliberais. In Tânia Franco (Org.), Trabalho, riscos industriais e meio ambiente : rumo ao desenvolvimento sustentável ? (p. 15-32). Salvador : Edufba.

Fleury, R. (2005). Terceirização no Serviço Público : a falacia da modernização e a porta para o nepotismo. Retirado em Junho, 01, 2006, de http:// www.pgt.mpt.gov.br/noticias.

Franco, T. \& Afonso, R. (1997). Acidentes de trabalho e mobilidade dos riscos industriais na Bahia. In Tânia Franco (Org.), Trabalho, riscos industriais e meio ambiente : rumo ao desenvolvimento sustentável ? (pp. 189-214). Salvador : Edufba. 
Franco, T., Druck, G., Borges, A. \& Franco, A. (1994). Mudanças de gestão, precarização do trabalho e riscos industriais. Caderno $\mathrm{CRH}, 21,68-89$.

Franco,T. (org.) (1997). Trabalho, Riscos Industriais e Meio Ambiente : rumo ao desenvolvimento sustentável ? Salvador : Edufba.

Freitas, C. (1996). Acidentes químicos ampliados : incorporando a dimensão social nas análises de riscos. Tese de doutorado, ENSPFIOCRUZ, CESTEH, Rio de Janeiro.

Freitas, C., Souza, C., Machado, J. \& Porto, M. (2001). Acidentes de trabalho em plataformas de petróleo da Bacia de Campos. Cadernos de Saúde Pública, 17, (1), 117-130.

Gitahy, L. (1994). Inovação Tecnologica, subcontratação e mercado de trabalho. São Paulo em Perspectiva, 8, (1), 144-153.

Gitahy, L., Rabelo, F. \& Costa, M. (1989). Inovação Tecnologica, relações industriais e subcontratação. Campinas : Instituto de Geociências IG Unicamp.

Godinho, L. (2003). Um Mosaico de classe : a terceirização na Rlam. Dissertação de Mestrado, Programa de Pós-Graduação em Ciências Sociais da Universidade Federal da Bahia, Salvador.

Grusenmeyer, C. (2007). Sous-traitance et accidents. Exploitation de la ase de données EPICEA. ACTES du XXXXII Congrès de la SELF (Société d'Ergonomie de Langue Française). Retirado em 2007, de http://www.ergonomie-self.org/self2007/ACTES2007.pdf.

Harvey, D. (1992). A condição pós-moderna. São Paulo : Loyola.

Hirata, H. (1997). Crise èconomique, sous-traitance et division sexuelle du travail : réflexions à partir du cas japonais. In B. Appay \& A. Thébaud-Mony (orgs.), Précarisation sociale, travail et santé. Paris : IRESCO.

Krein, J., Gimenez, D. \& Biavaschi, M. (2003). As Cooperativas de Mão de Obra e os Tribunais Regionais do Trabalho. Revista da ABET, III, (1), 3-28.

Lavinas, L., Sorj, B., Linhares, L. \& Jorge, A. (1998). Trabalho a Domicílio : novas formas de contratação. Genéve : Departamento de Políticas de Desenvolvimento, OIT.

Lima, J. \& Soares, M. (2002). Trabalho Flexível e o Novo Informal. Caderno CRH, 37, 163-180.

Lima, J. (1997). O Custo Nordeste : flexibilização produtiva e trabalho na indústria do vestuário. Seminário "Produção flexível e novas institucionalidades na América Latina", Rio de Janeiro.

Lima, J. (1998). Trabalho assalariado e trabalho associado : experiências de terceirização da produção. XXIII Reunião Nacional da ANPOCS, GT : Trabalho e Sociedade, Caxambu/MG.

LIMA, J. (2004). O Trabalho autogestionario em cooperativas de produção : o paradigma revisitado. Revista Brasileira de Ciências Sociais, 19, (56), 45-62.

Miranda, C. (s/d). Ataque ao Mundo do Trabalho : Terceirização e seus Reflexos na Segurança e Saúde do Trabalhador. Retirado em Junho, 01, 2006, de http://www.saudeetrabalho.com.br.

Paiva Abreu, A. \& Sorj, B. (orgs.) (1993). O Trabalho Invisível. Estudos sobre Trabalhadores a Domicílio no Brasil. Rio de Janeiro : Rio Fundo Editora.

Paiva Abreu, A., Jorge, A. \& Sorj, B. (1994). Desigualdade de Gênero e Raça : o Informal no Brasil em 1990. Estudos Feministas. Rio de Janeiro : CIEC/ECO/UFRJ.

Piccinini, V. (2004). Cooperativas de trabalho de Porto Alegre e flexibilização do trabalho. Sociologias, 12, 68-105.

Piore, M. \& Sabel, C. (1984). The second industrial divide. New York : Basic Books. 
Pochmann, M. (1998). Velhos e novos problemas do mercado de trabalho no Brasil. Indicadores Econômicos FEE, 26, (2), 103 - 118.

Pochmann, M. (1999). O Trabalho sob fogo cruzado : desemprego e precarização no final do século. São Paulo : Contexto.

Queiroz, C. (1998). Manual de Terceirização. São Paulo : Editora STS.

Ruas, R. (1993). Relações entre trabalho a domicílio e redes de subcontratação. In Alice Abreu \& Bila Sorj (orgs.), O Trabalho Invisível. Estudos sobre Trabalhadores a Domicílio no Brasil. Rio de Janeiro : Rio Fundo Editora.

Souza, C. \& Freitas, C. (2002). Perfil dos acidentes de trabalho em refinaria de petróleo. Revista de Saúde Pública, 36, (5), 576-573.

Thébaud-Mony, A. \& Druck, G. (2007). Terceirização : a erosão dos direitos dos trabalhadores na França e no Brasil. In Graça Druck \& Tânia Franco (Orgs.), A perda da razão social do trabalho : terceirização e precarização (pp. 23-58). São Paulo : Boitempo.

Thébaud-Mony, A. (1990). L'envers des sociétés industrielles : approche comparative francobrésilienne. Paris : Ed. L'Harmattan.

Thébaud-Mony, A. (2000). L'industrie nucléaire. Sous-traitance et servitude. Paris : Inserm/EDK.

Vidal-Gomel, C., Olry, P., Lanoë, D. \& Jeanmougin, H. (2007). La livraison de béton : système de travail et prévention des risques profesionnels. ACTES du XXXXII Congrès de la SELF (Société d'Ergonomie de Langue Française). Retirado de http:// www. ergonomie-self.org/self2007/ ACTES2007.pdf. www.flexibilizacao.ufba.br www.pgt.mpt.gov.br/noticias www.sind.org.br

\section{NOTAS}

1. Nos EUA o termo é outsourcing, na França sous-traitance ou exteriorisation; na Itália subcontrattazione, na Espanha subcontratación (Carelli, 2003). No Brasil utiliza-se também o termo subcontratação, mas de forma menos usual.

2. Annie Thébaud-Mony (2000) faz uma ótima discussão acerca da palavra «exteriores» para designar os trabalhadores subcontratados e que fazem a manutenção da indústria nuclear na França, fazendo a seguinte pergunta: «...Pourquoi désigner comme 'extérieurs' des travailleurs qui participent pleinement au processus de production nucléaire, en le rendant possible par des interventions de maintenance aussi régulières dans le temps nécessaires pour le maintien en état de marche des installations?» (op.cit, p.2).

3. Ver Monografia de Walmir Maia Rocha Lima Neto, Marcelle de Oliveira Cardoso, Luciana Lacerda de Oliveira, Claudia Peçanha M. Ribeiro: "Primeirização: solução para a flexibilização e precarização? - um estudo de caso», Curso de Psicologia Organizacional/Unifacs, 2005.

4. Lavinas et al. (1998), apoiando-se em estudo de Breton para a França, informa: “(...) três elementos caracterizam o teletrabalho: o teletrabalho é uma atividade realizada à distância, isto é, fora do perímetro onde seus resultados são esperados; quem dá as ordens não pode controlar fisicamente a execução da tarefa. $O$ controle é feito com base nos resultados, não sendo, portanto, direto; esta tarefa é feita através do uso de computadores ou outros equipamentos de informática e telecomunicações" (op. cit, p. 4).

5. Ver Lavinas et al. (1998) «Trabalho a Domicilio: novas formas de contratação». Os autores apresentam estudos de caso sobre novas formas de trabalho a domicílio que diferem das tradicionais, como é o caso de uma micro-empresa de informática onde todos os funcionários trabalham em suas respectivas casas, ou o caso de uma indústria de aparelhos eletrônicos, que 
permitiu a opção pelo trabalho a domicílio de suas funcionárias na área de montagem. Fazem referência, também, ao caso da Kodak do Brasil, que “(...) reconhece o sucesso da sua estratégia de basear em casa, e não nos locais da firma, os funcionários das áreas de venda e assistência técnica. Estes permanecem assalariados da empresa, isto é mantêm vínculo empregatício, e respondem a metas estabelecidas por ela. Os ganhos de produtividade alcançados têm-se mostrado evidentes e inquestionáveis, segundo depoimentos de executivos da Kodak. No entanto, queixas contra a empresa foram feitas por alguns desses trabalhadores a domicílio, reivindicando pagamento de horas extras ou cobertura de despesas com restituição de aluguel de espaço não pago pela empresa na moradia do trabalhador. Essas são, aliás, as alegações que acabam sendo negociadas na Justiça do Trabalho pelos empregados que foram deslocados para seus domicílios, na hora das demissões." (op. cit, p. 5).

6. Pesquisa realizada pela Gazeta Mercantil em 2000 e publicada na forma de CD.

7. Segundo a OCB - Organização do Cooperativismo do Brasil.

8. Em levantamento realizado junto a $4^{\circ}$ Região (Rio Grande do Sul) do Tribunal Regional do Trabalho, dos 150 acordãos em 2001, que tratavam sobre reconhecimento da relação de emprego de «cooperativados», em processos julgados, 67 reconheceram a relação de emprego, os demais casos tiveram julgamentos diversos, sendo que 64 não reconheceram a condição de empregado e somente 14 afirmaram a condição de cooperativado, conforme Krein, Gimenez e Biavachi, (2003).

9. Segundo Lima (2004), as "pragmáticas" referem-se àquelas voltadas para a terceirização de atividades com o objetivo de reduzir custos com a força de trabalho. A aceitação pelos trabalhadores é igualmente "pragmática", objetivando a manutenção de emprego (Lima, 2004, p. 51).

10. Trata-se da pesquisa "Terceirização: uma década de mudanças na gestão do trabalho Módulo 1: Uma década de terceirização nas empresas contratantes", realizada pelo CRH/UFBA entre 2004/2005, em cooperação técnica com a DRT/BA na execução do trabalho de campo junto às empresas, com o patrocínio da Petrobrás. Tem como ponto de partida a pesquisa desenvolvida pelo CRH/UFBA, entre 1993 e 1995, sobre a Terceirização na Bahia, também em cooperação técnica com a DRT-BA, integrando o Projeto MTb/PNUD BRA 91/013.

11. Foram utilizados os seguintes instrumentos de pesquisa: i) questionário com 94 questões abertas e fechadas; ii) quadros pontuais e iii) tabelas, para reconstituir séries históricas de informações referentes ao período compreendido entre 1993 e 2003. Ademais, foram consultados diversos documentos das empresas e seus respectivos sites.

12. Vale esclarecer que a atualização da amostra de 44 empresas anteriormente pesquisadas (em 1993/1995) resultou numa amostra de 35 empresas na pesquisa de 2004/05. O banco de dados foi alimentado com as informações de 21 respondentes dentre as 35 , sendo consideradas válidas as informações de 19 empresas, correspondendo a 54,3\% do conjunto de empresas pesquisadas em 2004/05.

13. Considerando tanto a pesquisa sobre a terceirização realizada em 199395 quanto a pesquisa mais recente, realizada em 2004/05, conforme explicitado em notas anteriores.

14. Todos esses aspectos merecem uma análise mais cuidadosa que, no entanto, não cabe no escopo deste capítulo.

15. «Um enunciado é o substrato do entendimento dominante da Corte em um dado contexto historico-social, servindo como orientação, tanto para a Casa, como para os demais orgãos da Justiça do Trabalho» (Carelli cit in Carrion, 2000).

16. Em 2003, as jornalistas Cássia Almeida/Ramona Ordoñez/Geralda Doca do Jornal o Globo realizaram uma série de reportagens intitulada A Terceirização que mata, informando sobre os acidentes na indústria do petróleo («das 133 vidas perdidas a serviço da Petrobrás de 1998 até agora, 102 foram de terceirizados, ou seja, 76\%, segundo a Federação Única dos Petroleiros (FUP) e a própria estatal. Este ano, houve dez mortes só uma de funcionário da Petrobrás»), e nas empresas de telecomunicações. 
17. Processo constatado no caso da indústria petroquímica da Bahia, onde o sindicato que reúne os pretoquimicos contratados diretamente pelas empresas passa a disputar «base sindical» com o sindicato dos metalúrgicos, que congrega os trabalhadores de manutenção, com o sindicato de vigilantes, e assim por diante, perpassando toda a cadeia de fragmentação engendrada com a crescente terceirização.

18. Em 2006, a Empresa Baiana de Desenvolvimento Agrícola S/A (EBDA), na Bahia, “...foi acionada pelo Ministério Público do Trabalho e será obrigada a afastar trabalhadores contratados irregularmente, realizando concurso público para preenchimento dos cargos vagos da casa. (...) a ação civil pública (ACP) foi julgada parcialmente procedente (...) na $18^{\mathrm{a}}$ Vara do Trabalho de Salvador. Garante não só o livre acesso dos trabalhadores via concurso, como assegura que a EBDA não renove ou faça novos contratos temporários sem respaldo na Constituição Federal. No caso de contratos celebrados por prazo determinado (após 5/10/1998), a ACP obriga o afastamento dos trabalhadores irregulares, dando um prazo de seis meses, após a decisão final, para a realização de concurso público. Prevê ainda uma multa de $\mathrm{R} \$ 5$ mil, por cada trabalhador mantido em contrariedade à condenação. (...) As terceirizações também foram alvo da ação do MPT. Os contratos com a Cooperativa de Trabalho, Apoio e Serviços Ltda - Cooptrab e com a Cooperativa do Trabalho dos Profissionais de Processamento de Dados Ltda - Tecnocoop demonstraram tratar-se de mera intermediação de mão-de-obra, sendo descaracterizado o sentido do cooperativismo." (www.prt5.mpt.gov.br).

19. A exemplo da condenação da Empresa Eternit, em 2004, por ter "exposto seus trabalhadores ao manuseio e exposição ao asbesto", pelo Ministério Público do Estado de São Paulo, determinando pagamento de indenizações, pensões vitalícias, planos de saúde a ex-funcionários adoecidos e ao registro de todos os trabalhadores que estão sob tratamento e que virão a se submeter, além do pagamento das custas do processo. (www.abrea.com.br)

\section{RESUMOS}

O objeto do artigo é a terceirização hoje no Brasil. Discute-se o processo de flexibilização e precarização do trabalho no Brasil, tendo por objeto de estudo, a terceirização/ subcontratação, enquanto uma das principias políticas de gestão e organização do trabalho no quadro da reestruturação produtiva. Apresenta uma síntese do processo de terceirização/ subcontratação nos últimos anos no país, em suas velhas e novas modalidades, e analisa os resultados empíricos recentes sobre a terceirização/subcontratação em empresas industriais com alto risco ambiental e para a saúde dos trabalhadores, na Região Metropolitana de Salvador/Bahia/Brasil, assim como indica as principais formas de resistência e contra-poderes construídos contra a precarização do trabalho e à terceirização

El objeto del artículo es la tercerización, en la actualidad, en Brasil. Se discute el proceso de flexibilización y precarización del trabajo en Brasil, tomando por objeto de estudio la tercerización/subcontratación, como una de las principales políticas de gestión y organización del trabajo en el cuadro de la reestructuración productiva. Presenta una síntesis del proceso de tercerización/subcontratación en los últimos años en el país, en sus viejas y nuevas modalidades y analiza los resultados empíricos recientes sobre la tercerización/subcontratación en empresas industriales con alto riesgo ambiental y para la salud de los trabajadores, en la Región 
Metropolitana de Salvador/Bahia/Brasil. Además, señala las principales formas de resistencia y contra-poderes construidos contra la precarización del trabajo y la terceirización.

L'objectif de l'article est de discuter la soustraitance aujourd'hui au Brésil. Nous discutons dans l'article le processus de flexibilisation et de précarisation du travail au Brésil, en prenant comme objet d'étude la sous-traitance, en tant qu'une des principales politiques de gestion et d'organisation du travail dans le cadre de la restructuration productive. Nous présentons une synthèse du processus de sous-traitance observé ces dernières années dans le pays, sous ses anciennes et nouvelles modalités, et nous analysons les résultats empiriques récents sur la soustraitance dans des entreprises industrielles à haut risque pour l'environnement et la santé des travailleurs, dans la Région Métropolitaine de Salvador/ Bahia/Brésil, de même que nous indiquons les principales de formes de résistance et de contre-pouvoirs construits contre la précarisation du travail et la sous-traitance.

The aim of this paper is to analyze current service outsourcing in Brazil. The process of flexibilization and increasing precariousness of labour in Brazil is discussed, focusing on service outsourcing/subcontracting, as one of the major policies for labour management and organization in the productive restructuring scenario. It presents a summary of the service outsourcing/subcontracting process during recent years in Brazil, bearing in mind its old and new modalities. It furthermore analyses the latest empiric results regarding service outsourcing/ subcontracting in industries with high risks for the environment and for workers¥ health, in the Metropolitan Region of Salvador/Bahia/Brazil. Moreover, it indicates the major forms of resistance and anti-establishment movements that were developed against the increasing precariousness of labour and against service outsourcing.

\section{ÍNDICE}

Mots-clés: travail, précarisation, sous-traitance

Palavras-chave: trabalho, precarização, terceirização (subcontratação)

Keywords: work, increasing precariousness, service outsourcing

Palabras claves: trabajo, precarización, subcontratación

\section{AUTORES}

\section{GRAÇA DRUCK}

Centro de Recursos Humanos, Faculdade de Filosofia e Ciências Humanas, Universidade Federal da Bahia, Brasil, CNPq druckg@gmail.com

\section{TÂNIA FRANCO}

Centro de Recursos Humanos, Faculdade de Filosofia e Ciências Humanas, Universidade Federal da Bahia

franctania@uol.com.br 